04

\title{
Формирование потоков дейтронов в малогабаритном высоковольтном сильноточном диоде с импульсной магнитной изоляцией
}

\author{
(C) А.Е. Шиканов, Е.Д. Вовченко, А.А. Исаев, К.И. Козловский, В.Л. Шатохин
}

Национальный исследовательский ядерный университет „МИФИ“, 115409 Москва, Россия

e-mail: vlshatokhin@mephi.ru

(Поступило в Редакцию 6 октября 2016 г.)

\begin{abstract}
Приведены результаты новых исследований по получению потоков ускоренных дейтронов в малогабаритном ионном диоде с импульсной магнитной изоляцией электронов. Плазменный анод диода формировался под действием излучения лазера с длиной волны $1.06 \mu \mathrm{m}$, длительностью импульса $10 \mathrm{~ns}$, энергией импульса излучения до $1 \mathrm{~J}$, плотностью мощности на мишени $5 \cdot 10^{15} \mathrm{~W} \cdot \mathrm{m}^{-2}$. Ускоряющее напряжение до $300 \mathrm{kV}$ создавалось с помощью генератора импульсного напряжения Аркадьева-Маркса с запасенной энергией $50 \mathrm{~J}$ при частоте повторения $1 \mathrm{~Hz}$. Изолирующее электроны магнитное поле более $0.6 \mathrm{~T}$ формировалось импульсом тока первого каскада генератора в спиральной линии перед катодом конической формы. Достигнуто устойчивое ускорение дейтронов до энергии $300 \mathrm{keV}$ с током до $1.5 \mathrm{kA}$ при длительности импульса $0.3 \mu \mathrm{s}$.
\end{abstract}

DOI: $10.21883 /$ JTF.2017.06.44524.2057

В работе [1] были опубликованы результаты, полученные сотрудниками НИЯУ МИФИ в процессе исследования импульсных малогабаритных диодов с магнитной изоляцией для генерации нейтронов, и проанализированы две возможности увеличения энергии и тока дейтронов - за счет повышения амплитуды ускоряющего напряжения и за счет повышения эмиссионной способности плазменного источника дейтронов. Первая связана с использованием высокостабильных генераторов импульсного напряжения (ГИН), собранных по схеме Аркадьева-Маркса, с амплитудой до $400 \mathrm{kV}$ и эффективной магнитной изоляцией диодного зазора [2-4]. Вторая достигается путем применения лазеров, способных генерировать импульсы излучения с энергией $W$ до $1 \mathrm{~J}$ в импульсе длительностью $\sim 10 \mathrm{~ns}$ для получения дейтериевой плазмы [5].

Использовать магнитную изоляцию в малогабаритных диодных системах для генерации нейтронов было впервые предложено в работе [6]. При этом возможны две схемы подавления электронной проводимости: постоянным магнитным полем с азимутальной симметрией [1-4] и импульсным магнитным полем спиральной линии, прилегающей к катоду $[1,5,7]$.

Эксперименты по формированию потоков ускоренных дейтронов в диодах с подавлением электронной проводимости полем постоянных магнитов [2,3] выявили недостатки, связанные со сложной конфигурацией магнитного поля и его неоднородностью. Они проявляются в невозможности создания во всем пространстве между катодом и фронтом лазерной плазмы индукции магнитного поля параллельно поверхности катода более $0.6 \mathrm{~T}$, требуемой для полного подавления электронной проводимости диода при $W>0.1 \mathrm{~J}$. Это приводит к пробой- ным явлениям в области диодного зазора и неполному извлечению дейтронов.

Авторами было установлено, что подобные недостатки в меньшей степени проявляются в диодах с импульсной магнитной изоляцией, рассмотренных в работах $[1,4,7]$. В настоящей работе приводятся результаты дальнейшего экспериментального исследования процессов формирования потоков ускоренных дейтронов в подобных диодах.

Для получения дейтериевой плазмы использовался лазер на иттрий-алюминиевом гранате, активированном неодимом, генерирующий в режиме модулированной добротности импульсы инфракрасного излучения $(\lambda=1.06 \mu \mathrm{m})$ с энергией $W \leq 0.85 \mathrm{~J}$ и длительностью $\tau_{l} \approx 10 \mathrm{~ns}$. Передний фронт лазерной плазмы играл роль анодной поверхности. Ускоряющее напряжение создавалось с помощью ГИН Аркадьева-Маркса, генерирующего в режиме холостого хода положительные импульсы с амплитудой $U_{0} \approx 400 \mathrm{kV}$ и длительностью более $10 \mu \mathrm{s}$. ГИН мог работать с частотой $1 \mathrm{~Hz}$.

Магнитное поле в диоде формировалось, как и в работе [4], с помощью спиральной линии, образующая поверхность которой имеет форму усеченного конуса. Принципиальное отличие от проводимого ранее эксперимента заключалось в использовании более мощного лазера, высокостабильного ГИН с параметрами, указанными выше, и оригинальной схемы его запуска на базе лазерного управляемого разрядника (ЛУР).

Схема экспериментальной установки представлена на рис. 1. Электродная система ионного диода находится в вакуумной камере. Процесс формирования потока ускоренных дейтронов на ионном коллекторе осуществлялся следующим образом. Импульс инфракрасного излучения, генерируемый лазером, фокусировался 


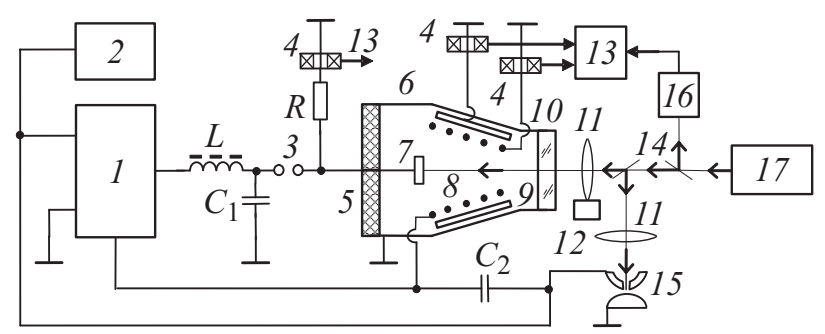

Рис. 1. Схема эксперимента по формированию дейтронного потока: 1 - ГИН (2-30 каскады), 2 - блок зарядки ГИН, 3 - разрядник-обостритель, 4 - пояса Роговского, 5 изолятор, $6-$ вакуумная камера, $7-$ плазмообразуюшая мишень, 8 - спиральная линия, 9 - ионный коллектор (катод), 10 - оптическое окно, $11-$ фокусирующие линзы, 12 - сканирующее устройство, 13 - осциллограф, 14 частично прозрачные зеркала, $15-$ ЛУР, $16-$ ФЭК, 17 лазер.

на твердую плазмообразующую мишень с плотностью мощности $\sim 5 \cdot 10^{15} \mathrm{~W} \cdot \mathrm{m}^{-2}$. Использовались мишени из дейтеридов титана и дейтерированного полиэтилена. Фокусирующая линза закреплялась на упругой подвеске, вибрирующей перпендикулярно трассе лазерного луча, что, согласно [8], обеспечивало сканирование пятна фокусировки по поверхности мишени для поддержания концентрации дейтерия вблизи поверхности мишени на фиксированном уровне.

С помощью частично прозрачного зеркала и собирающей линзы часть лазерного излучения направлялась для запуска ЛУР с характерным временем запаздывания разряда $\leq 50 \mathrm{~ns}$, через который накопительная емкость $C_{2}=0.25 \mu \mathrm{F}$, находящаяся под напряжением $\approx 15 \mathrm{kV}$, разряжалась на спиральную линию конической формы с углом наклона $\approx 20^{\circ}$. В результате в спирали формировался импульс тока с фронтом нарастания $<500 \mathrm{~ns}$ и амплитудой $\approx 8 \mathrm{kA}$. Расчет показал, что в этом случае с учетом тока, индуцируемого в коллекторе, охватывающем спираль и также имеющем подобную спирали коническую форму, индукция магнитного поля в области, прилегающей к коллектору, а также вблизи проводников спирали должна существенно превышать критические значения [1], при которых электроны с коллектора и проводников спирали гарантированно не должны захватываться плазменным облаком и инициировать пробой в ускоряющем зазоре.

В рассматриваемой схеме узел ЛУР- $C_{2}$ одновременно являлся первым каскадом ГИН. После его срабатывания емкости ГИН разряжались на формирующую линию $L C_{1}$ $\left(L>1 \mathrm{mH}, C_{1}=30 \mathrm{pF}\right)$, соединенную через разрядникобостритель с плазмообразующей мишенью. Сопротивление $R=100 \mathrm{k} \Omega$ предназначено для создания потенциала корпуса установки на втором электроде разрядникаобострителя и одновременно для измерения импульса напряжения на плазмообразующей мишени. Наличие формирующей линии обеспечивало временную задержку между формированием импульса ускоряющего напряжения и временем распространения плазмы с анода для выполнения необходимых условий синхронизации

$$
\frac{H}{V} \approx \sqrt{L C_{1}} \approx 200 \mathrm{~ns},
$$

где $H$ - продольный размер коллектора (катода), $V \sim 10^{5} \mathrm{~m} / \mathrm{s}$ - скорость разлета лазерной плазмы.

Ток ускоренных дейтронов и ток в цепи спиральной линии измерялись осциллографом с помощью поясов Роговского. На рис. 2 представлены импульсы дейтронного тока при различных энергиях лазерного излучения, полученные в результате обработки экспериментальных осциллограмм методом кубической интерполяции, необходимые для теоретического анализа возможного нейтронного выхода. Точкой временного отсчета являлся сигнал с фотоэлектронного коаксиального преобразователя (ФЭК), на который отводилась малая часть излучения лазера (рис. 1).

Полученные экспериментальные данные позволяют оценить перспективы генерации нейтронов в рассматриваемой диодной системе. Выход нейтронов за импульс определялся по формуле

$$
Q(W) \approx \frac{n}{e} \int_{0}^{\tau} d t \cdot I_{D}(W, t) \int_{0}^{e U(t)} d E \frac{\sigma(E)}{F(E)},
$$

где $n$ - концентрация ядер реагентов в нейтронообразующей мишени, $e-$ элементарный электрический заряд, $\tau$ - длительность импульса дейтронного тока по основанию, $U(t)$ - зависимость ускоряющего напряжения от времени, $F(E)$ - потери энергии дейтроном на единице длины мишени, $\sigma(E)$ - микросечение ядерной реакции. Зависимости тока дейтронов и напряжения от времени

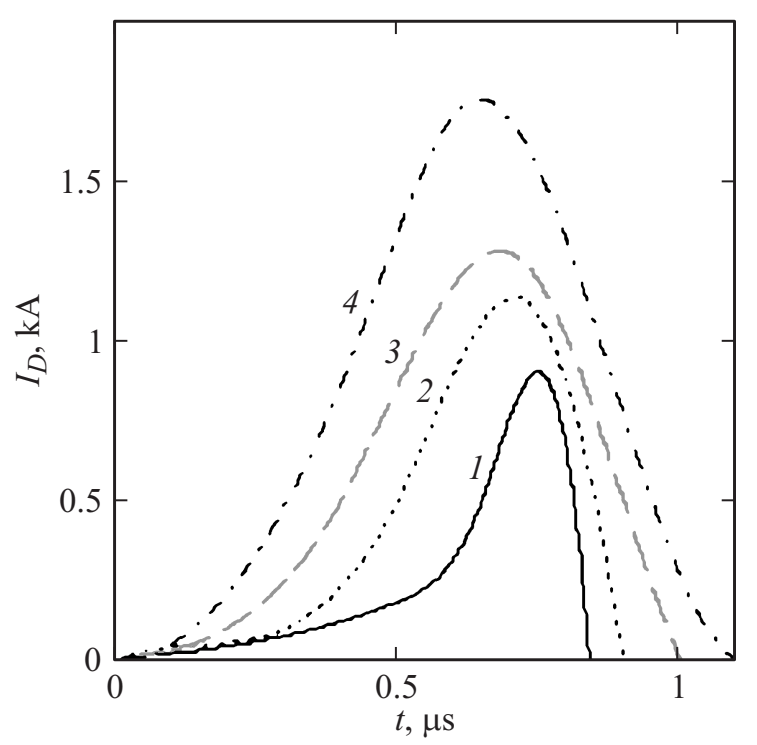

Рис. 2. Ток диода $I_{D}(t)$ при энергиях лазера: $1-80,2-200$, $3-380,4-750 \mathrm{~mJ}$. 
Результаты расчета $-Q(W)$ neutrons/pulse

\begin{tabular}{l|c|c|c|c}
\hline \multirow{2}{*}{$\begin{array}{l}\text { Ядерная } \\
\text { реакция }\end{array}$} & \multicolumn{4}{|c}{$W, \mathrm{~mJ}$} \\
\cline { 2 - 5 } & 80 & 200 & 380 & 750 \\
\hline$T(d, n)^{4} \mathrm{He}$ & $2 \cdot 10^{10}$ & $4 \cdot 10^{10}$ & $6 \cdot 10^{10}$ & $8 \cdot 10^{10}$ \\
$D(d, n)^{3} \mathrm{He}$ & $1.5 \cdot 10^{8}$ & $3 \cdot 10^{8}$ & $4 \cdot 10^{8}$ & $6 \cdot 10^{8}$
\end{tabular}

брались из осциллограмм, полученных в результате эксперимента. Оценки нейтронного выхода были сделаны для ядерных реакций $T(d, n)^{4} \mathrm{He}$ и $D(d, n)^{3} \mathrm{He}$, традиционно используемых в малогабаритных генераторах нейтронов. При расчете функции энергетических потерь использовалась модель, описанная в работе [9]. Расчет проводился для мишеней из титана, равномерно насыщенного тритием или дейтерием до коэффициента стехиометрии $k=1.5$. Результаты расчета нейтронного выхода представлены в таблице.

Проведено экспериментальное исследование диода для генерации нейтронов с лазерно-плазменным источником дейтронов и импульсной магнитной изоляцией спиральной линией конической формы при энергии лазерного импульса и амплитуде ускоряющего напряжения, достигающих соответственно $W=0.75 \mathrm{~J}$ и $U_{0}=300 \mathrm{kV}$.

Показано, что в указанных диапазонах $W$ и $U_{0}$ соблюдается пропорция между амплитудой дейтронного тока и энергией лазерного импульса.

Выполненные для данных диапазонов $W$ и $U_{0}$ расчеты показали, что нейтронный выход в полный телесный угол при использовании ядерной реакции $T(d, n)^{4} \mathrm{He}$ может достигать $10^{11}$ neutrons/pulse.

Работа поддержана Министерством образования и науки РФ, Соглашение № 14.575.21.0049. (RFMEFI 57514X0049).

\section{Список литературы}

[1] Диденко А.Н., Шиканов А.Е., Козловский К.И., Шатохин В.Л., Пономарев Д.Д. // Физика плазмы. 2014. Т. 40. № 11. C. 1025-1034.

[2] Шиканов А.Е., Вовченко Е.Д., Козловский К.И., Шатохин В.Л. // Письма в ЖТФ. 2015. Т. 41. Вып. 10. С. 104-110.

[3] Шиканов А.Е., Вовченко Е.Д., Козловский К.И. // Атомная энергия. 2015. Т. 119. Вып. 4. С. 210-215.

[4] Козловский К.И., Пономарев Д.Д., Рыжкков В.И., Цыбин А.С., Шиканов А.Е. // Атомная энергия. 2012. Т. 112. Вып. 3. С. 182-184.

[5] Ананьин О.Б., Цыбин А.С., Шиканов А.Е., Козловский К.И. // Атомная энергия. 2013. Т. 115. В. 2. С. 115-118.

[6] А.c. № 766048 СССР. Импульсная нейтронная трубка / Д.Ф. Беспалов, К.И. Козловский, А.С. Цыбин, А.Е. Шиканов. 1979.
[7] А.c. 1468275 СССР. Импульсная нейтронная трубка / В.М. Гулько, В.Н. Дыдычкин, К.И. Козловский, Н.Ф. Коломиец, Б.В. Михайленко, А.Е. Шиканов, К.И. Яковлев 1985.

[8] А.c. 1107678 СССР. Сканирующее устройство лазерного источника ионов / И.И. Вергун, Ю.А. Дьячихин, К.И. Козловский, А.Е. Шиканов. 1982.

[9] Богданович Б.Ю., Нестерович А.В., Шиканов А.Е. // Атомная энергия. 2010. Т. 109. Вып. 5. С. 293-298. 